\section{The H1N1 vaccine plan}

Health Canada would like to set the record straight on the claims made in the Aug. 31, 2009, editorial "The H1N1 vaccine race: Can we beat the pandemic?" "In particular: Although we are treating this vaccine as a new product, which it is, the extra work involved in the authorization was largely completed before this current pandemic was declared. Furthermore, as the regulatory review of the adjuvant has already been completed as part of the review of the H5N1 vaccine, no additional data on the adjuvant itself is being asked for by Health Canada. Our remaining evaluation activities are focused on the H1N1 antigen component of the vaccine. In summary, there will be no delay in getting a pandemic influenza vaccine to Canadians due to regulatory requirements. Health Canada is working closely with the manufacturer to review proposed production timelines for Canada and we will be ready to make a decision on the authorization of an adjuvanted and a non-adjuvanted pandemic vaccine as soon as one becomes available and a public health determination has been made to use one, the other, or both.

\section{Elwyn Griffiths PhD DSc}

Director General, Biologics and Genetic Therapies Directorate, Health Canada

\section{REFERENCE}

1. Hébert PC, MacDonald N. The H1N1 vaccine race: Can we beat the pandemic? CMAJ 2009. DOI:10.1503/cmaj.091560

For the full letter, go to: www.cmaj.ca/cgi/eletters /cmaj.091560\#186702

DOI:10.1503/cmaj.109-2021

\section{CMA on the vaccine plan}

Re: The H1N1 vaccine race, Aug. $31^{1}$ The CMAJ's readers would have been better served by a piece that acknowledged the legitimate arguments supporting the Health Canada position on the H1N1 vaccine. First, it is not known when those countries that have opted for a standard vaccine will be ready to release a safe product; suggesting it will be far in advance of the Canadian product is misleading speculation. Second, the use of adjuvants not only gives better cross-protection against mutating flu virus strains, but also "leverages" the standard vaccine, reducing the amount required for an effective dose by a significant amount. The implications of this should be obvious: A resource in short supply becomes available to an entire population. Finally, even if it is necessary to wait a few weeks to have the supply of adjuvant vaccine, it will be available to the vulnerable and general population alike as the anticipated pandemic increases into the winter months, notably, at a time when other nations with standard vaccine may be unable to guarantee coverage. Journal readers deserve editorials that are distinguished from polemics by presentation of both sides of a debate.

\section{Anne Doig MD}

President, Canadian Medical Association

\section{REFERENCE}

1. Hébert PC, MacDonald N. The H1N1 vaccine race: Can we beat the pandemic? CMAJ 2009. DOI:10.1503/cmaj.091560

For the full letter, go to: www.cmaj.ca/cgi/eletters /cmaj.091560v1\#189137

DOI:10.1503/cmaj.109-2024

\section{CMAJ editor responds:}

We thank both Anne Doig and Elwyn Griffith for noting that we did not accurately characterize Canada's position on approval of the H1N1 vaccine ${ }^{1}$. Our readers should be made aware that in mid-September, the US Food and Drug Administration approved all H1N1 vaccines including the live attenuated H1N1 vaccine.

\section{Paul Hébert MD MHSc \\ Editor-in-Chief, CMAJ}

For the full letter, go to: www.cmaj.ca/cgi/eletters /cmaj.091560\#190431

DOI:10.1503/cmaj.109-2025

\section{H1N1 patients in ICU}

At the Health Sciences Centre in Winnipeg, Manitoba, 27 patients were admitted to the adult medical intensive care unit (MICU) with confirmed H1N1 respiratory failure between Apr. 23 and June 30. Patient demographics of the Winnipeg ICU cohort were similar to 10 reported cases in Michigan. Both patient populations suffered from severe ARDS and required prolonged ventilatory support. We observed substantial increases in the use of sedative agents and empiric antibiotics during this recent outbreak in our adult MICU. As part of pandemic planning and capacity building, we encourage pharmacists, clinicians and planners to consider the amount of sedation and antimicrobials necessary to care for $\mathrm{H} 1 \mathrm{~N} 1$ patients in the ICU.

\section{Alfred Gin PharmD, Anand Kumar MD and colleagues}

Health Sciences Centre, Winnipeg, Man.

For the full letter, go to: www.cmaj.ca/cgi/eletters /cmaj.091560\#186706

DOI:10.1503/cmaj.109-2022

\section{Response to Dr. Miller}

Re: Response to "Statin-associated myopathy," published in Research, July $7^{1}$. With the selection criteria clearly stated and concomittant medication disclosed, we fail to see why our study should be considered "deeply flawed." Or indeed more "flawed" than numerous existing studies, which are based on a fraction of the number of our carefully documented cases. We also regret the lurid reports by the popular press, however, we must decline all responsibility. Tabloids publish what they want.

\section{Annette Draeger MD}

University of Bern, Bern, Switzerland

\section{REFERENCE}

1. Mller D. Fear of statins? [letter].CMAJ 2009;181 (6-7):399.

For the full letter, go to: www.cmaj.ca/cgi/eletters /181/1-2/E11\#180617

DOI:10.1503/cmaj.109-2019 